

\title{
IDENTIDAD Y RECONFIGURACIÓN TIEMPO-ESPACIO DE LOS DESPLAZADOS HACIA MEDELLÍN: LECTURA EN LAS PRÁCTICAS DE OCIO
}

\author{
IDENTITY AND SPACE-TIME RECONFIGURATION ON DISPLACED POPULATION TOWARDS \\ MEDELLIN: READING IN LEISURE PRACTICES
}

\author{
Rubiela Arboleda Gómez ${ }^{1}$ \\ Saúl Franco Betancur ${ }^{2}$
}

\section{Resumen}

\begin{abstract}
Este artículo es producto de la investigación "El ocio en la reconfiguración identitaria de los desplazados hacia la ciudad de Medellín" ${ }^{3}$ (2011-2013). La disertación pretende dar cuenta del tiempo en relación con el espacio, leído desde las prácticas de ocio, y su significado en la emergencia de identidades, consecuencia del destierro. Metodológicamente, se sitúa en el marco de la etnografía reflexiva implementada con entrevistas y diarios de campo. Por este medio, se ha llegado a comprender que la modificación en la percepción del tiempo en el tránsito rural-urbano atraviesa las prácticas de ocio y se traduce ontológicamente en identidades emergentes.
\end{abstract}

Palabras claves: Ocio, Tiempo, Espacio, Identidad.

\section{Abstract}

This article is a result of the investigation "Leisure in the identity reconfiguration of the displaced towards Medellín" (2011-2013). The dissertation seeks to explain time in relation to space, read from leisure practices and its meaning in the emergence of identities as a result from exile. Methodologically lies under reflexive ethnography implemented throughout interviews and field notes. Hereby it has come to understanding that the change on the time's perception in rural-urban transit passes through leisure practices and it translates ontologically in emerging identities.

Keywords: leisure, time, space, identity.

Fecha de recepción: 16 de octubre de 2014

Fecha de aprobación: 15 de marzo de 2015

Para citar este artículo:

Arboleda, R. y Franco, S.A. (2014). Identidad y reconfiguración tiempo-espacio en desplazados hacia Medellín: lectura en las prácticas de ocio. Lúdica Pedagógica, (21), 121-130.

\footnotetext{
1 Doctora en Estudios Científicos Sociales. ITESO (Jalisco-Tlaquepaque), Magíster en Problemas Sociales Contemporáneos, Antropóloga y Licenciada en Educación Física. Universidad de Antioquia. Docente Instituto de Educación Física Universidad de Antioquia. Integrante grupo: Ocio, expresiones motrices y sociedad. Correo electrónico: ursula59@hotmail.com

2 Magíster en Motricidad y Desarrollo Humano, Licenciado en Educación Física. Universidad de Antioquia. Docente Instituto de Educación Física Universidad de Antioquia. Integrante grupo: Ocio, expresiones motrices y sociedad. Correo electrónico: saulfb@yahoo.es

3 Los autores dirigieron el proyecto entre 2011 y 2013.
} 


\section{INTRODUCCIÓN}

El desplazamiento forzado ${ }^{4}$ ha caracterizado la historia colombiana, particularmente desde finales del siglo XX y lo que va del XXI. Según datos del informe de la Consultaría para los Derechos Humanos y Desplazamiento (CODHES), durante 2012, unas 256.590 personas fueron desterradas, acumulando 5.701 .996 de víctimas desde 1985 en el país.

Estar en situación de desplazamiento implica el sacrificio de los referentes de identidad y desdibuja los nexos culturales trascendentales para el individuo y la colectividad. Estos inmigrados se hallan en un contexto sociocultural que irrumpe como laberinto azaroso por lo desconocido y diferente a su entorno, lo que connota el vaciamiento de sentidos con respecto a aquello que soporta la existencia. El desplazado se ve lanzado a otras dinámicas sociales espacio-temporales, lo que le demanda la búsqueda de estrategias frente a su cotidianidad (en el estar ahí) para rehacer sus horizontes de posibilidad.

Las prácticas habituales se ven sometidas a las vicisitudes de la sobrevivencia y se tornan, en ocasiones, ajenas para sí mismo y para el receptor; de tal manera que el ocio, como experiencia ontológica inscrita en el diario acontecer, exige ajustes que reclaman atención e interpretación. En esta deriva se enfatizará en la transformación en la percepción del tiempo-espacio en el tránsito rural-urbano, leída desde las prácticas de ocio, y en razón a la emergencia de identidades, consecuencia del desplazamiento forzado hacia la ciudad de Medellín.

\section{TRAZOS CONCEPTUALES}

La pregunta por la relación ocio, tiempo e identidad en los desplazados compromete conceptos que obedecen a intereses y despliegues teóricos densos, provenientes de las ciencias sociales y la filosofía. Empero, se han seguido aquí nociones estratégicas que admiten su tratamiento por la vía empírica.

Para el caso del desplazamiento, se ha adoptado la siguiente definición:

4 En este texto, toda referencia al destierro debe leerse como desplazamiento forzado.
Es desplazado toda persona que se ha visto forzada a migrar dentro del territorio nacional abandonando su localidad de residencia o actividades económicas habituales, porque su vida, su integridad física, su seguridad o libertad personales han sido vulneradas o se encuentran directamente amenazadas, con ocasión de cualquiera de las siguientes situaciones: Conflicto armado interno, disturbios y tensiones interiores, violencia generalizada, violaciones masivas de los Derechos Humanos, infracciones al Derecho Internacional Humanitario u otras circunstancias emanadas de las situaciones anteriores que puedan alterar o alteren drásticamente el orden público (Ley 387 de 1997, Título I, "Del desplazado y de la responsabilidad del Estado". Artículo 1).

Las acepciones vinculadas al ocio presentan multiplicidad de significados: fiesta, juego, descanso, diversión, deporte, recreación, derecho o distracción. Estas designaciones exhiben una tensión con el tiempo medible en función del trabajo o tiempo productivo, el que se asume como labores obligantes y poco placenteras. El ocio, entonces, presenta una relación directa con el tiempo: un tiempo cuantificado, el que se considera ha de ser superado por un tiempo otro, más cercano a la sensación de libertad (desatadura de la constricción productiva).

El ocio, como construcción social, debe ser estudiado en el contexto de las prácticas locales y develar en estas las resistencias, manifestaciones y discursos que problematizan el proceso de civilización en marcha, anclado en las formas de producción y en un tiempo lineal.

Para este estudio, ha sido pertinente retomar los aportes del Instituto de Deporte y Recreación, de Medellín (INDER, 2011), que entiende el ocio como:

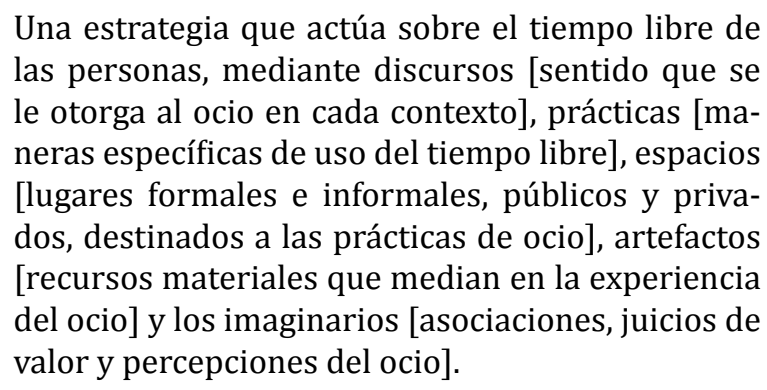

Con dicha noción, se pretende aquí explicitar el nexo entre la transformación en la experiencia ontológica del tiempo -rastreada desde la percepción y reconfiguración-, en relación con el espacio -abordado desde lo 
rural/campo y urbano/ciudad-, acontecida con el desplazamiento forzado hacia Medellín.

La identidad se comprende como una construcción social. Como dimensión compleja, participa en la propia heterogeneidad de cualquier grupo social; no puede considerarse monolítica, esencialista ni unívoca, toda vez que la contemporaneidad marcada por un movimiento general de eclosión de las sociedades globalización, migraciones y relocalizaciones, ha producido exacerbación de las identidades particulares. Hay pues, una mixtura de identidades en las que se mueve el sujeto, se transita por ellas e, incluso, puede darse una simultaneidad de manifestaciones de estas. La identidad es un bastimento elaborado en la tensión entre las personas que están en contacto, hasta llegar a las fronteras de los grupos: juego de interacciones en el que se delimitan singularidades y colectividades (Arboleda, 2009). En este sentido, apunta Reguillo (2001):

Es importante pensar que una identidad no es la suma de sus atributos, sino la relación compleja y multidimensional que los portadores de estos atributos establecen con el entorno, no se trata de una determinación, sino de una mediación. Así, lo que interesa es utilizar la identidad como concepto heurístico y pensarla como una matriz cultural que se alimenta de varias fuentes en el tiempo y en el espacio. [...] Operación que permite hacer el análisis espacial del modo cómo se relacionan con la ciudad y con los otros (p.11)

Tiempo y espacio operan como constitutivos de la identidad. En el caso de los desplazados, estas categorías sufren transformaciones que afectan, justamente, esa necesidad existencial de la autodefinición refrendada por los otros en un locus y un cronos conocidos.

El tiempo está ligado insoslayablemente al espacio.

Tiempo y espacio son interdependientes y se constituyen mutuamente. No existe uno sin el otro, no hay espacio sin tiempo y viceversa, y no podemos extraer uno independiente del otro sin caer en la distorsión. El tiempo es el 'otro' gran rostro de la realidad junto con el espacio (Vicens, 2004, p. 39).

La experiencia tiempo-espacio se corresponde con las formas de hacer, concebir y representar el universo sociocultural, lo que explica el impacto existencial que conlleva el destierro obligado, en el que tanto la percepción del tiempo como su vínculo con el territorio se ven transformados. La dimensión temporo-espacial es constitutiva de la existencia, he ahí su lugar ontológico.

La reflexión filosófica ha buscado una comprensión del tiempo y su significado en relación con el ser y las formas de vida. Para Heidegger (1962), el ser se manifiesta en el horizonte del tiempo como: permanencia, constancia, devenir, como eternidad. Sin embargo, este horizonte se temporaliza solo en razón de uno de los éxtasis del tiempo, el presente, el ahora (Hayling, 1996, p. 318). Nietzsche (1972), por su parte, señaló el poder mítico, en la cosmología occidental, del tiempo lineal y su proyección en la historia. Advierte que una de las consecuencias de entender el tiempo de manera abstracta y lineal es pensar que es posible acelerarlo a voluntad.

Acelerar el tiempo es la forma que ha adoptado la tecnología para dominar el mundo. La aceleración es el nombre de ese tiempo que se impone en las representaciones de los sujetos que habitan la urbe. Enunciados como "el progreso va hacia adelante y no se puede parar" o "la tecnificación es ineludible" expresan, de cierta forma, una alienación temporal de los sujetos: la certeza de que el tiempo es ajeno a la vida y que sigue su curso independiente de las acciones y pensamientos humanos. Los actores entrevistados no escapan a estas lógicas del tiempo y, por ello, el discernimiento aquí parte de las acepciones manifiestas en sus discursos, percibido en el tránsito rural-urbano e interpretado en la tensión tiempo lineal (ciudad)/tiempo cíclico (campo).

Para el concepto de espacio, es relevante el referente de territorio: categoría significativa del bastimento de la identidad; espacio simbólico, cargado de sentido, colectivamente construido, que desborda toda idea de mensurabilidad. Para Molina (2012):

No es un lugar o sitio delimitado y desarticulado. Por el contrario, expresa la unión, el interrelacionamiento, la afectación de todo y de todos (...). Es simetría naturaleza-cultura. En tal sentido, es un elemento sustantivo de la historia de los pueblos y se expresa en su memoria e identidad como agrupamiento. Es el suelo, el subsuelo y el cosmos pero también son las personas, los objetos y los espíritus. Integra espacio y pensamiento geográfico, de allí que las actuaciones de los humanos sobre la tierra tienen consecuencias directas sobre el territorio, sobre las personas y la sociedad (p. 1017). 
Interesa aquí la díada: rural (campo)/urbano (ciudad), que ha sido resignificada teóricamente en el intento de reducir la dicotomía y comprenderla como categorías subsumidas la una en la otra: lo urbano ha penetrado lo rural y este último en lo urbano. Sin embargo, la producción de conocimiento realizada aquí a partir de los testimonios recabados, insiste oponer estos espacios, definiendo el uno como contrario al otro. Y en esa contraposición emerge la transformación en la percepción del tiempo: de un tiempo cíclico, vinculado al campo, a un tiempo lineal, propio a la ciudad.

Remedi (2000) sostiene que la ciudad ha tenido grandes trasformaciones y en estas, quizás la más notable y emblemática sea la modificación sustancial del espacio social, que implica y expresa nuevas formas de reorganización real y simbólica de la ciudad, como resultado de una manera diferente de vivirla, de relacionarse y de pensarla. Destaca que en este proceso de cambios la organización espacial de las desigualdades -que ha dado lugar a ciudades fracturadas en zonas de distintas clases sociales o culturas- ha levantado muros (reales y mentales) infranqueables que impiden encontrarse, verse, imaginarse e, incluso, pensarse como pares, vecinos, conciudadanos.

Si bien la adjetivación de desplazado corresponde a una identidad imputada (Uribe, 2002), los otros, como constitutivo ineluctable de la identidad, otorgan al llegado esa distinguibilidad (Giménez, 2000).

Un líder dice: se identifican porque se siente que no hacen parte de la ciudad; se sienten como perdidos, tienen una actitud corporal de espera... como que de la ciudad les caiga algo (...) en los viejos se les nota la actitud, alguien que ha vivido en el campo y llega a Medellín, donde no tienen el río, no pueden ir a pescar, no pueden cantar, no conocen a nadie y la actitud es de agachar la cabeza y son como esperando la muerte (A2 Diversidad Étnica) .

Para el desplazado, en la ciudad confluyen nuevos factores: demandas y ofertas, influencias recíprocas entre desterrados y receptores, adaptaciones y desafíos, que hacen de ésta un entramado de signos, originando una experiencia que se traduce en afectaciones esenciales del ser y promueve un ser otro.

\section{METODOLOGÍA}

Para atender la inquietud por la reconfiguración identitaria, desde la dimensión del ocio en relación al tiempoespacio en población desplazada hacia Medellín, se siguió una ruta orientada por la etnografía reflexiva, complejización metodológica que reconoce la pluralidad de la realidad y de las estrategias para abordarlas. Un enfoque cualitativo que se asienta en la relevancia, para la estructuración del conocimiento, de las interpretaciones personales de la experiencia en el mundo y en el estar sociocultural. Un especie de correlato de la denominada filosofía de la sagacidad: "modo de pensar y explicar el mundo que oscila entre la sabiduría popular (sentido común) y la sabiduría didáctica, una sabiduría y un pensamiento racional explicados por determinados individuos dentro de una comunidad" (Santos, 2009, p. 101).

Método que reivindica al actor como creador de significados desde su biografía e interrelaciones (Minayo, 2009). El investigador se compromete en el acto y es así objeto y sujeto de la indagación. Una ida y vuelta del dato que permite que quien problematiza la realidad se redescubra y legitime en el proceso. No es otro, ajeno, a develar, sino que es un nosotros declarado en el efecto reflexivo.

Empíricamente, se abordaron 26 personas desplazadas (A1) provenientes de contextos rurales. Se incluyeron afrodescendientes, indígenas y mestizos. Se delimitaron los siguientes lugares del denominado Centro de Medellín: plaza minorista, iglesias San José, Veracruz y Candelaria; parques Bolívar, San Antonio y Berrío, Unidad de Atención al Desplazado (UAO) y albergue temporal de Villahermosa. Se abordaron cuatro representantes de los receptores (A2) y seis de las instituciones vinculadas a los desplazados (A3).

Para recabar la información, se siguieron protocolos de entrevistas definidas según los actores (A1, A2, A3); se hicieron observaciones para reconstruir en los contextos aquellos matices que escapan a los testimonios. Se llevaron diarios de campo con una guía convencional, adaptada por cada investigador.

Estratégicamente, el ocio se rastreó desde las prácticas (actividades asociadas al tiempo libre) y los escenarios (equipamientos como parques tradicionales y temáticos, metro y metrocable). El espacio se organizó en las subcategorías: ciudad (referencias a la urbe) y campo 
(entornos rurales). El tiempo, categoría que emergió en el estudio y tomó fuerza a partir de la reiteración en los testimonios, se abordó desde las percepciones (apreciaciones ante la transformación del tiempo) y reconfiguraciones (ajustes ante la transformación de la experiencia del tiempo).

Los datos se objetivaron y categorizaron de forma artesanal y las entrevistas fueron transcritas y codificadas. Para este artículo, se retomaron los testimonios de los entrevistados y se recodificaron con el tipo de actor (A1, A2 o A3) y lugar de procedencia.

El análisis se orientó desde un cuadro relacional que permitió articular los diferentes momentos del proceso en razón del trabajo de campo: las estrategias de acercamiento, los objetivos y las categorías analíticas en estos contenidas; se elaboraron las inferencias según las dimensiones y se ubicaron en virtud de la estructura final (Franco y Arboleda, 2013).

\section{EJEMPLO DEL ANÁLISIS EN EL CUADRO RELACIONAL}

\begin{tabular}{|c|c|c|c|c|}
\hline Objetivos & Preguntas & $\begin{array}{l}\text { Categorías } \\
\text { subcategorías }\end{array}$ & Estrategias & Inferencias \\
\hline $\begin{array}{l}\text { 1. Develar en las } \\
\text { prácticas de ocio las } \\
\text { transformaciones en la } \\
\text { percepción del tiempo } \\
\text { en el tránsito rural- } \\
\text { urbano en desplazados } \\
\text { hacia Medellín }\end{array}$ & $\begin{array}{l}\text { ¿Cuáles son las } \\
\text { diferencias en esa } \\
\text { percepción del tiempo } \\
\text { al llegar a la ciudad? } \\
\text { ¿Cuáles son los ajustes } \\
\text { en el nuevo espacio } \\
\text { ante esa percepción? } \\
\text { ¿Cómo media esa } \\
\text { percepción del tiempo } \\
\text { en las prácticas de } \\
\text { ocio? }\end{array}$ & $\begin{array}{l}\text { Tiempo: } \\
\text { percepción } \\
\text { reconfiguración } \\
\text { Espacio: } \\
\text { campo } \\
\text { ciudad } \\
\text { Ocio: } \\
\text { prácticas } \\
\text { escenarios }\end{array}$ & $\begin{array}{l}\text { Entrevistas, } \\
\text { observación no } \\
\text { participante. }\end{array}$ & $\begin{array}{l}\text { El tiempo en Medellín se percibe } \\
\text { acelerado y ajeno. } \\
\text { Hay un extrañamiento de un } \\
\text { tiempo apropiado, connatural al } \\
\text { campo. } \\
\text { La modificación en la percepción } \\
\text { representa desventajas y desafíos } \\
\text { para el desterrado. } \\
\text { Las transformaciones tiempo- } \\
\text { espacio generan ajustes } \\
\text { identitarios. }\end{array}$ \\
\hline
\end{tabular}

Consideraciones éticas: se procuró ofrecer a los actores información que les significara un aprendizaje. Los testimonios fueron codificados preservando el anonimato de los interlocutores en campo; se realizó un retorno de la información y un proceso de aprobación de las interpretaciones con los actores: lectura de diarios y participación en presentaciones públicas.

Interpretación reflexiva: la vida y la cultura están reguladas por las coordenadas tiempo-espacio, las mismas que resultan afectadas por el desplazamiento: desarraigo del territorio como referente de sentido y de un tiempo en el que nos hemos instalado, desde el cual sincronizamos los ritmos cotidianos. "La rutinización es vital para los mecanismos psicológicos mediante los cuales un sentido de confianza o de seguridad ontológica es sustentado en las actividades prácticas de la vida social" (Giddens, 1994, p. 48); es la reiteración cotidiana de las prácticas sociales, lo que posibilita la reflexividad del agente, pues si las prácticas sociales fuesen solamente efímeras (y/o únicas), no sería posible el conocimiento por el sujeto del ambiente de actuación, hecho que podría imposibilitar la acción innovadora y creativa. Las prácticas de ocio hacen parte de la experiencia vital que conforma la cotidianidad, por esto, con el cambio obligado de hábitat se generan alteraciones en las prácticas incorporadas y realizadas usualmente: desrutinización propia del destierro que entraña un cambio profundo en aspectos sustantivos al ser y deviene en la emergencia de un sujeto otro.

\section{Percepción}

Tránsito rural-urbano: las transformaciones de las ciudades latinoamericanas, consecuencia de los procesos de reorganización que marcan la sociedad contemporánea, conforman espacios urbanos orientados cada vez más hacia la oferta de servicios y prácticas empresariales. La ciudad fabril -caso Medellín- se hace menos visible y otras características van apareciendo para transfigurar el panorama citadino y la vida de los ciudadanos (Tabares et al., 2007). 
Los cambios económicos y sociales están sucediendo a una velocidad vertiginosa, se han transformado los modos tradicionales de vida, y el tiempo es un valor ponderable en términos de producción. La globalización económica versus la identidad local, la homogeneización cultural, el avance tecnológico y científico, los riesgos medioambientales, etc. no son cuestiones neutras y aisladas, sino que plantean nuevas necesidades y dilemas que demandan resolución, entre estas: redefinir el concepto y los límites del estado de bienestar, y reconocer en éste la función destacada del ocio.

El destierro ha generado el imperativo de sobrevivir en la tensión rural-urbana, lo que requiere una ubicación y control territorial en función de las posibilidades efectivas de proveerse el sustento. La magnitud de la urbe, y la complejidad social y política que la asisten, ha provocado temor en el inmigrado: la incomprensión de la inmediatez muta en desafío para alcanzar el dominio que demanda la satisfacción de necesidades. Como lo expresan: "al llegar vi todo muy raro, me perdía, sentía miedo. Yo aquí no hablo sino lo preciso; es muy difícil... si no se conoce, peor" (A1 Peque).

El temor ante el nuevo espacio se ilustra con los barrios, espacio habitacional que significa refugio inmediato $\mathrm{y}$, paradójicamente, riesgo vital, por la violencia que obliga a un desplazamiento intraurbano. La errancia impide así la domesticación de los espacios, lo que limita la experiencia del ocio, de la cual se espera un regodeo espiritual e íntimo, que se ve empañado por un estado de ánimo "constreñido, lesión ontológica que perfila a ese ser otro con trazos como: sensación de estrés, encierro y aturdimiento en la urbe". Así lo dicen:

Me siento acongojado, triste, con momentos muy amargos. En la noche creo que me van a robar. Todo es duro aquí... uno no tiene vida: no duermo, no como (A1 Betulia). Aquí me siento muy aburrido, acongojado, triste, con momentos muy amargos. Mi niño que se murió... aquí es muy bravo, mucha inseguridad, mucho peligro con los carros, en la noche que lo van a robar, que lo coja un carro o una bicicleta, que lo levantara a uno o a uno de los niños (A1 Mutatá).

Los retos en su vida campesina tenían otra lógica, fundamentada más en el conocimiento de su medio y la necesidad de mejorarlo, mientras que en Medellín se enfrentan a desafíos en el marco de la consecución del sustento y la adaptación a un espacio que se constituye a los ritmos del proyecto moderno. Testimonios al respecto: "el centro de Medellín es horrible por la bulla, la contaminación, la inseguridad" (A1 Tolima). "Aquí es muy bravo; mucha inseguridad, mucho peligro con los carros...el ruido" (A1 Betulia).

La evocación del campo es recurrente en sus verbalizaciones, como queriendo investir la ciudad con sus paisajes, sus saberes y rutinas; resisten la urbe porque no tienen alternativa, pero añoran estar en su entorno conocido, trabajando lo sabido: sembrar, cultivar y cuidar sus animales: "lo que más extraño del Chocó es el río, y los tíos, allá era grande, muchas fincas, muchas frutas, muchos árboles" (A1 Acandí).

Las posibilidades de ocio para los desplazados en Medellín son limitadas por varias razones: económicas (situación de desempleo o indigencia), el tipo de ocupación (trabajo informal) y su manera de convivir (hacinamiento en albergues o nomadismo forzado). Quienes han logrado conseguir vivienda de interés social, manifiestan que las construcciones habitacionales adolecen de espacios para la socialización y para la lúdica (Tabares, 2007, p. 45). Así lo dicen: "me siento muy mal aquí, no hay como uno estar allá con esa libertad, aquí uno se siente encerrado" (A1 Mutatá).

La dimensión ontológica del ocio se arraiga, en términos materiales y simbólicos, al dominio y a la compresión del territorio, lo cual provee aprendizajes posibilitadores de las prácticas de divertimento. Para los desplazados, el campo representa un espacio marcado por los ríos, las montañas, las zonas abiertas, la floresta y el aire: paisaje favorecedor de los ritmos propios y apropiados, en sus distintas acepciones; por ello impostar lo citadino, desde la experiencia del ocio, no es posible para el desplazado. "Añoro bañarme en la quebrada, ir a pescar... así se me iba el tiempo, aquí me gustaría ir al cine, pero no conozco, no sé dónde quedan los teatros, nunca he ido" (A1 Betulia).

\section{DEL TIEMPO CÍCLICO AL TIEMPO LINEAL}

Un correlato del impacto ante el tránsito del espacio rural al urbano se manifiesta en la percepción y las representaciones del tiempo, categoría clave para la comprensión del ocio: la ciudad se vive a mayor velocidad y en situaciones de estrés y preocupación. Del tiempo rural dicen: "eran seis horas de camino para 
salir al pueblo. En la finca tenía toda la comida: gallinas, marranos. Mataba un ternero y lo salaba. Se llegaba a ritmo de mulas" (A1 Urrao).

El acercamiento empírico a la realidad de los desplazados hacia Medellín en el estudio marco de esta reflexión ha mostrado que el tiempo es asumido en relación con la producción; sus testimonios dejan leer la tensión entre tiempo laboral y tiempo libre. Gimeno afirma que la dimensión social del tiempo clasifica a los individuos, tiene un poder regulador sobre las personas y marca pautas de organización en sus vidas (2008). Dicho orden estructura las relaciones, dependencias y jerarquías entre ellos. Empero, la situación de desplazamiento impide el ingreso en un tiempo organizacional, está condicionada, porque solo acceden a empleos informales y de difícil clasificación (desempleo, subempleo, trabajo informal), por esto, para ellos, todo es tiempo libre.

Conceptualmente, el aprovechamiento del tiempo libre se puede entender como el uso constructivo que el ser humano hace de él, en beneficio de su enriquecimiento personal y del disfrute de la vida. No obstante, en la comunidad aquí visitada, el tiempo está sometido a la atención de necesidades básicas, lo que modifica los modos de organizar su vida (interacciones familiares y sociales), como testimonian: "cuando no trabajo pidiendo limosna, me voy a la iglesia a escuchar la palabra del señor o pa' donde mis amigas" (A1 Soruco).

Tanto el tiempo laboral como el tiempo libre son eventuales. La lógica producción-ocio está atravesada por vicisitudes que transforman la experiencia de lo uno y lo otro en una suerte de tiempo indeterminado; de ahí que emerja esta pregunta: ¿cómo contar con tiempo libre si no se es empleado? Por eso responden:

¡De recreación nada! ¡Qué vagancia tan horrible...! mejor dicho: todo es tiempo libre (A1 Betulia). Me siento muy mal sin trabajo... yo no, primero como le dije yo me inventé un empleo, tengo que trabajar para poder inventarme la comida. El tiempo libre mío es el obligado, porque mire que no estoy libre porque aquí estoy obligado a esperar una respuesta. Entonces no tengo tiempo libre, yo trabajo todos los santos días (A13 Carepa).

Para Durkheim (1968), el tiempo es un dato colectivo $\mathrm{y}$, en esta medida, los miembros de una sociedad tienen una comprensión compartida de este, constituyéndose en un componente de la conciencia colectiva. Esta es pues otra transformación significativa en el sujeto del desplazamiento: llegan a Medellín, donde el tiempo está organizado y deviene en patrón estructurante, cuya existencia es previa a los individuos. Una ciudad que impone su peculiar orden, regula las actividades sociales de una comunidad matizada por una particular experiencia del tiempo e intenta asimilar a los diferentes grupos, incluso a quienes acaban de arribar. Elias (1989) le concede al carácter colectivo del tiempo el valor de aglutinante social, gracias a su capacidad reguladora. Con el destierro, se fractura la grupalidad y la percepción integradora de este se desvanece en el tiempo que conforma a la otra comunidad, la receptora. Como expresan: "para la atención en salud, tuve que ir una semana a la Alcaldía. Hoy vine a pie, llegué a las cinco y son las once y aquí me ve" (A1 Santander). "Hace tres meses coloqué el derecho de petición y esta es la hora que no he tenido respuesta..." (A1 Samaná).

La consideración del tiempo para la población procedente del campo recuerda un tiempo de las cosas, de la gente, de la vida, el tiempo del transcurrir de las actividades humanas, en el que las prácticas de ocio correspondían a las dinámicas propias, pautadas por los contextos sociales de circunscripción: un tiempo cíclico. "Madrugaba a la cinco, le daba el tetero a ella, preparaba la comida, miraba las gallinitas, los marranitos, sembrábamos plátano... yuca y cuando había tiempo sembrábamos maíz" (A1 Mutatá).

Esa percepción contrasta con la dominancia citadina del tiempo fraccionado, introyectado como un tiempo metronómico, con una programación determinada: un tiempo lineal. Así relatan: "en el albergue tenemos horarios para los alimentos, para ver la televisión, para lavar la ropa, para lavar la loza. Otras normas tienen que ver con los hábitos" (A1 Samaná). Este tránsito entre la percepción de tiempo cíclico y el tiempo lineal ha propiciado maneras de recomposición indentitaria, marcadas por el desasosiego ante un tiempo desconocido que los acosa y precipita hacia una articulación, también forzada, a un nuevo estilo de vida: otra vida. De su territorio dicen: "prefiero el campo por la tranquilidad, los animales, los suyos" (A1 Urrao). De la ciudad dicen: "me mantengo aburrida porque aquí hay mucha gente, mucho ruido, todo es acelerado y muy rápido, el tiempo no alcanza" (A1 Córdoba). 
El ritmo del tiempo lineal se acentúa por la contundente mediación del dinero como garantía de la subsistencia en la ciudad; tiempo que se aprecia insuficiente para el cumplimiento de tareas e impone a los desplazados un reordenamiento de sus prácticas en razón de un cronos que los regula y acecha. Se perciben agitados, con un espacio-tiempo cada vez más reducido para hacer sus cosas y donde los costos de sus vidas aumentan, porque, como lo manifiestan, en Medellín "todo se tiene que pagar": "aquí todo tiene uno que comprarlo... todo es plata, entonces uno así ni puede comer" (A1 Carupia). "Toca trabajar mucho y a veces no alcanza la plata porque toca pagar todo, los pasajes y lo más necesario, no me queda para nada más" (A1 Campamento).

La percepción del tiempo en los desplazados se transforma, al llegar a la ciudad, en un tiempo otro; un tiempo del otro, un tiempo en un espacio otro, otros tiempos percibidos y ajustados en relación a lo desconocido, al extrañamiento y a lo que hay por descubrir. Asumir los nuevos tiempos toca con la capacidad de adaptación, aceptación y reinvención en la urbe: reconfiguración que penetra la identidad.

\section{LA RECONFIGURACIÓN: ESCENARIOS Y PRÁCTICAS DE OCIO}

Frente al ocio, Medellín se erige como un espacio desconocido e indómito, lo que significa una limitación a la hora de acceder a sus escenarios; la falta de domino territorial impide identificar las diferentes alternativas citadinas y se transforma en obstáculo para su ejercicio. Los espacios que se proponen para las prácticas de ocio o que operan en el imaginario de los desterrados representan una particular simbólica de Medellín. Sitios como el parque de Berrío, el parque Norte, el Jardín Botánico, el Pueblito Paisa, entre otros, afloran en los discursos de los entrevistados, bien porque los conocen, los frecuentan o se instalan como expectativa. Pareciera que apropiarse de estas zonas alegóricas los invistiera de la idiosincrasia lugareña, que les retorne una figura identitaria. Como manifiestan: "me gustaría conocer el Pueblito Paisa, tiene buena fama, todo el mundo habla, 'que vamos pa'l pueblito' y dicen que es muy bueno y lo invitan a uno" (A1 Betulia).

De cara a los escenarios deportivos, los desplazados identifican los más emblemáticos, y es evidente que algunas administraciones promueven los recursos y elaboran programas en los que logran articularse muchos de ellos. Pero queda la grieta, porque no se garantiza la estabilidad, los discursos recogidos aquí dan cuenta de posibilidades truncas y de la renuncia a prácticas que agenda la ciudad: "me tocó salirme, porque tenía muchas deudas, entonces no podía ir a practicar, era con el INDER, tenía que ir a entrenar los martes y los jueves, y no podía porque me tocaba pagar" (A1 Campamento). "Yo me siento alegre en el programa, lo malo es que tengo que pagar, ¿y de dónde voy a sacar plata para esto?" (A1 Mutatá).

Una vez más, el dinero obstaculiza las prácticas de ocio en la ciudad: "me gustaría ir al Chocó, por el río, porque acá lo único amplio que hay para bañarse son las piscinas y hay que pagar, pero allá cuando uno se quiere meter al río, se puede bañar todo lo que quiera" (A1 Mutatá).

La asistencia a los estadios, por ejemplo, está mediada por las filiaciones a los distintos equipos, aspecto que toca con la identidad. Seguir un equipo desborda la intención de divertimento y se emparenta con trazos definitorios del sujeto, éste y su hinchada significan un anclaje efectivo como referente del sí mismo con relación a los demás. Ese es otro choque del desplazado al dejar su terruño porque pierde la alternativa de disfrutar y experimentar las emociones, regodeos y tristezas que le acarrea su filiación deportiva. Un entrevistado dice: "no voy al estadio porque no soy hincha de los de aquí, sigo al Deportes Tolima, el de mi tierra" (A1 Tolima).

El desplazamiento violenta también la alternativa de la pasión y la identificación con un equipo, mutila así una posibilidad real de ocio en relación con la identidad. Los afrodescendientes desplazados, por ejemplo, prefieren las fiestas o bailaderos, como dice un líder: "lo que hemos visto es que ellos construyen sus prácticas de ocio. Me tocó ver un bailadero en un asentamiento, una casita que adaptaron y se usa para juegos de azar. En una comunidad formada en la emergencia de la urbe son muy clave las prácticas de ocio: las hacen donde estén y son más autóctonas" (A2 Diversidad Étnica).

La reconfiguración se explicita en algunas prácticas de ocio en la que se observa la desinstitucionalización del tiempo, puesto que no hay mediación de itinerarios preestablecidos; están allí simplemente como 
un acontecer de su vida trashumante en la ciudad. Así cuentan: "nosotros estuvimos por allá de casualidad, pasamos pa'l trabajo y vimos un grupo de mujeres y nos metimos y ahí sí bailamos porque la música era muy chévere y vino mucha gente" (A1 Soruco). También se identificaron prácticas como: tertuliar, salir de la ciudad, contemplar, prácticas deportivas, turistear, descansar, juegos de azar, caminar hacia lugares en las afueras de la ciudad, ir a los charcos y bañaderos, jugar al futbol, ver televisión (Franco y Arboleda, 2013).

Esta dilución entre el tiempo producción y el tiempo libre que conforma un tiempo indeterminado y la reconfiguración se manifiesta en relación con prácticas en apariencia ajenas al ocio, que ellos ubican en el tiempo libre: "en mi tiempo libre hablo con mis hijos para explicarles la violencia que hay aquí, la violencia que vivimos, los vicios que hay aquí no se veían en el Chocó" (A1 Samaná).

En suma, las maneras de instalarse en un tiempo-espacio desconocido se traducen en desrutinización y desdibujamiento de las prácticas propias que no se pueden conservar, con lo que se violan los acervos culturales que dan sustento al sujeto y dan paso a una reconfiguración en un ser otro, en una identidad emergente, también forzada.

\section{COROLARIO: ¿EL SER OTRO?}

En los desplazados se asiste a una transformación en la experiencia tiempo-espacio. Ese traslado del tiempo propio, adquirido a través de todas sus historias, al tiempo con ritmo de ciudad produce extrañeza para quien llega en situación de destierro. Las modificaciones en estas dimensiones ontológicas participan en el proceso de ajustes identitarios necesarios en la adaptación a la ciudad. Dichos cambios penetran las alternativas factibles para las prácticas de ocio que ingresan en un tiempo indeterminado.

El tiempo para los desplazados es indeterminado, es asumido como lapso para trabajar y, al no estar inscritos al sistema de regulación del empleo formal, perciben sus actividades de sustento como tiempo libre, tiempo no controlado por otro. El ocio se vincula más al tiempo reglado que a las prácticas que lo alimentan. El derecho y la misma percepción del ocio quedan subsumidos en la necesidad. Esta percepción pone en jaque el tiempo institucional y los lanza a otra forma del tiempo frente a la que no tiene insumos para interpretarla, de tal manera que se diluye la línea entre el tiempo laboral y el tiempo ocio.

La ciudad se escribe con una narrativa originada en un tiempo lineal, en la lógica de la producción y asociada a la industria, a la tecnología, al capitalismo, al proyecto modernizador y al reconocido y juzgado afán de progreso medellinense. La cotidianidad de los campesinos, ahora migrados, correspondía al ejercicio de sobrevivencia rural: la labranza, la agricultura, la pesca, la ganadería y minería obedecían a cadencias marcadas por un tiempo de simultaneidades, un tiempo cíclico que atiende los ritmos naturales y sociales (Vicens, 2004 , p. 14). Se ingresa en un tiempo urbano atomizado por la enunciación de "proyectos de ciudad" versus un tiempo rural que se arraiga en la añoranza.

El cambio en la percepción del tiempo en el espacio urbano genera una suerte de subjetividades suspendidas en una ambigüedad: la velocidad en la percepción del tiempo se convierte en un valor en sí mismo y la lucha contra el tiempo, destruye al tiempo mismo, generando sujetos de angustia. La celeridad acusada por los desterrados de cara a la vida en Medellín señala un impacto incorporado e insoslayable para habitar esta ciudad que no da tregua y en la que cada paso tiene un precio. La urbe no logra ser apropiada como un lugar para el ocio.

No obstante, el ocio, como constitutivo antropológico y como dimensión ontológica, demanda prácticas de enunciación a las cuales los desplazados no pueden renunciar. Si bien la experiencia del ocio, toda vez que está cruzada por la categorías espacio-tiempo, se altera la ingresar a un escenario no habitual, sus prácticas devienen mediadoras del proceso adaptativo y de reconfiguración identitaria. El ocio, como posibilidad de gozar, disfrutar, admirar, relacionar, y ensanchar la imaginación, opera aquí como potencializador de la existencia. He ahí su investidura política. 


\section{REFERENCIAS BIBLIOGRÁFICAS}

Arboleda, R. (2009). El cuerpo: huellas del desplazamiento. El caso de Macondo. Medellín: Hombre Nuevo.

CODHES. (2012). Informe anual. Recuperado de htpp:// www.codhes.org/index.phpption.com

Durkheim, E. (1968). Las formas elementales de la vida religiosa. México: Colofón.

Elias, N. (1989). Sobre el tiempo. Madrid: Fondo de Cultura Económica.

INDER Medellín (2011). El ocio, la recreación y el tiempo libre en el INDER Medellín. Algunas propuestas para su constitución. Documento inédito.

Franco, S. y Arboleda, R. (2013). El ocio en la reconfiguración identitaria de los desplazados hacia la ciudad de Medellín. En Colección Expomotricidad. Medellín: Funámbulos

Giddens, A. (1994). Sociología. Madrid: Alianza Universidad.

Giménez, G. (2000). Territorio, cultura e identidades. En Rosales, R. (ed.), Globalización y regiones en México (pp. 19 -33). México: Porrua.

Gimeno, J. (2008). El valor del tiempo en educación. Madrid: Morata.

Hayling, A. (1996). Relectura heideggeriana de Kant: el tiempo como horizonte ontológico y posibilidad de la metafísica. Rev. Filosofía, XXXIV, 83-322.
Heidegger, M. (1962). El ser y el tiempo. México: Fondo de Cultura Económica.

Minayo, M. (2009). La artesanía de la investigación cualitativa. Buenos Aires: Lugar.

Molina, V. (2012). De juegos y territorios. Compensaciones otras del ocio en sociedades de la periferia. Revista Educación física y deporte, 31(2), 1011-1117.

Nietzsche, F. (1972). Así habló Zaratustra. Madrid: Alianza Editorial.

Reguillo, R. (2001). Las derivas del miedo Intersticios y pliegues en la ciudad contemporánea. Guadalajara: ITESO.

Remedi, G. (2000). La ciudad latinoamericana S. A. Henciclopedia. Recuperado de http://www. elobservatorio.info/latinoamericana.htm

Santos, B. (2009). Una Epsitemología del sur. Buenos Aires: Siglo XXI.

Tabares, F., Blandón, M., Franco, S., Ossa, A. y Molina, V. (2007). Ciudad lúdica, elementos para la construcción de una sociedad solidaria y del bienestar. Cuadernos de Ocio y Sociedad, 1 (1/2), 41-50.

Uribe, M. (2002). Desplazamiento forzado interno. Notas para un debate. Desde Región, (37).

Vicens, J. (2004).Tiempo y cambio social. Valencia: Germania. 